\title{
Urban Planning for a Renewable Energy Future: Methodological Challenges and Opportunities from a Design Perspective
}

\section{Han Vandevyvere ${ }^{1, *}$ and Sven Stremke ${ }^{2}$}

1 Department of Architecture, Urbanism and Planning, KU Leuven, Kasteelpark Arenberg 1, B-3001 Leuven, Belgium

2 Landscape Architecture Group, Environmental Sciences Department, Wageningen University and Research, Droevendaalsesteeg 3, 6708PB, Wageningen, The Netherlands;

E-Mail: Sven.Stremke@wur.nl

* Author to whom correspondence should be addressed; E-Mail: han.vandevyvere@asro.kuleuven.be; Tel.: +32-16-321361; Fax: +32-16-321984.

Received: 7 May 2012; in revised form: 11 June 2012 / Accepted: 11 June 2012 /

Published: 18 June 2012

\begin{abstract}
Urban planning for a renewable energy future requires the collaboration of different disciplines both in research and practice. In the present article, the planning of a renewable energy future is approached from a designer's perspective. A framework for analysis of the planning questions at hand is first proposed. The framework considers two levels of inquiry: the technical environmental aspect, and its wider embedding in sustainable development. Furthermore, life cycle analysis and exergy studies are discussed for their application potential in design. An altered trias energetica as proposed in earlier publications appears to remain a robust concept for low exergy, renewable energy based urban design. When considering sustainable development, environmental assessments shall be completed by an inquiry of the socio-cultural, economical, juridical, aesthetical and ethical aspects characterizing the planning or decision process. The article then presents a number of practical design principles that can help envisioning a built environment that can be sustained on the basis of renewable energy sources. In accordance with the altered trias energetica concept, elements of passive urban energy design, exergetic optimization of energy provision systems and the sourcing of renewable energy are identified, and their respective potentials assessed.
\end{abstract}


Keywords: energy transition; built environment; renewable energy; sustainable urban development; energy potential mapping; regional planning; sustainable energy landscape; energy-conscious design

\section{Introduction}

The way by which the transition towards a renewable energy future and the transition towards sustainable cities can be geared to one another presents a major challenge for research and practice.

Sustainable building measures taken at the level of the individual building (i.e., micro-scale), such as increased insulation levels or solar-based energy provision, have become common practice but these must not be considered in isolation from questions related to the larger scale energy infrastructure (i.e., macro-scale). An additional and increasingly important level of intervention, the meso-scale, has to be considered next to the micro and the macro-levels [1,2]. This holds true for both energy provision and sustainable urban development issues. In terms of energy provision one may think of CHP or boiler plants for district heating and cooling, geothermal applications serving groups of buildings or grouped solar arrays. In terms of urban planning, questions regarding urban compactness, morphology and building orientation, related mobility effects, or the exchange of waste heat are examples of how urban planning may influence the overall energy consumption figures. Because of the many interrelations between 'energy' and the 'built environment', it is essential to coordinate the sustainability efforts in both fields of application. As a matter of fact, the urban fabric with its energy behavior in terms of demand and supply must be regarded as a 'whole system' in exchange with its larger environment. In this paper we will focus on the energy aspects of such whole systems approach, however without neglecting the overarching perspective of sustainable development.

The intended optimizations - we may hypothesize at the outset of this paper-will be scale- and context dependent. It may, for example, make more sense to renovate an existing compact urban district with related advantages in terms of combined energy consumption for buildings and mobility, than to aim at developing a new passive housing district on a greenfield outside the city where inhabitants may primarily depend on car traffic. The better performance of each single passive house in terms of energy consumption may indeed be overruled by the amount of energy needed for the increased traffic demand of its inhabitants. Another critical factor that has been studied by Stöglehner and Narodoslawsky is the energy consumed by the construction and maintenance of new infrastructure networks in low-density settlements [3].

Similar observations can be made regarding the integration of energy technologies at different scale levels within the overall energy infrastructure, and in particular within smart grids. As such, it could be more efficient to construct a solar farm outside an urban district rather than to install PV-panels or solar boilers on each individual building of the same district. Location and land use pressure, spatial quality, orientation and shading, investments, maintenance, emissions and nuisance control are factors that require a proper trade-off for the given context.

The quantitative, technical optimization of building related energy scenarios can develop along two axes, by assessing environmental impacts on the one hand, and by considering costs and benefits on 
the other hand. A combination of both parameters is however possible as well. This can, for example, be achieved by including environmental costs within an economic assessment [4].

Apart from environmental and economical evaluations however, socio-cultural, juridical, aesthetical and ethical considerations should come to complete the assessment when the goal is to achieve integrated sustainable development [5-8]. A typical example within the built environment is the trade-off between heritage value and improvement of the energy performance: it is unlikely that packing an iconic art nouveau building with an external insulation layer would be considered a good option. If modeling such decisions is desired, a multi-criteria decision analysis will have to be brought in. It becomes clear that at this level, both quantitative and qualitative factors will have to be considered. Several urban sustainability tools account of this fact, but respond to it in different ways $[6,9,10]$.

The present paper will discuss this problem through two key questions. Firstly, which types of information and assessment method are available to select the most sustainable urban energy scenarios? And secondly, what can be the constituent parts of a built environment that supports renewable energy based functioning?

The resulting overview is constituted through a literature review that targets different research fields: life cycle assessment studies, energy and exergy research, urban morphological studies, and integrated urban sustainability evaluation. Combining output from these different disciplinary fields allows drawing up a systematic overview of the current challenges and opportunities for designing sustainable cities that make use of renewable energy sources.

\section{Theoretical Framework and Literature Discussion}

For the present analysis we consider two major levels of assessment. On the one hand, the environmental performance of a given urban (energy) system, and on the other hand its integrated sustainability. By the latter we mean the quantitative-qualitative evaluation that considers socio-cultural, economic, juridical, aesthetical and ethical aspects as a complement to the set of environmental indicators.

\subsection{Environmental Assessments}

\subsubsection{Life Cycle Assessment}

Life Cycle Assessment (LCA) is a method to analyze the impacts on the environment resulting from a given process, e.g., the construction, use and demolition of a building. It is a well-established and regulated method [11] that is now finding its way into the evaluation of the built environment, from single construction components over buildings to entire urban fragments. It typically considers a series of impact categories like climate change, resource depletion, eco-toxicity or human health risks. The aggregation of all impacts into a single 'score' or 'environmental cost' is however optional and remains contested, e.g., [12]. This is because aggregation requires weighting of the different environmental effects, and as such involves normative decisions (for example, considering human health as more important than ecosystem health or vice versa; methodological difficulties of monetizing environmental impacts in case of expression as an environmental cost), e.g., [13]. For the present discussion, the LCA of energy systems is the most important factor to be considered, e.g., $[12,14]$. 
Despite its possible critics, the LCA of energy systems permits to reasonably identify technologies with less environmental impact, independent of their energetic or exergetic efficiency (see 2.1.2). Therefore, an LCA is of paramount importance to assess the environmental sustainability of energy sources and conversion technologies. An example is the evaluation of bio-fuels through LCA. Whereas bio-fuels may seem very interesting on the basis of their potential carbon-neutrality, an LCA of the entire process chain may reveal severe impacts that result in a score that is worse than that of fossil fuels [15].

At the demand side, the LCA of buildings or larger parts of the urban tissue (such as entire neighborhoods) permits to reduce aversive environmental impacts of such built structures. The method allows, for example, us to assess if the surplus impact associated with the use of additional insulation materials is compensated by the reduced energy consumption figures of the building under consideration, e.g., [16]. At the higher scale levels of urban tissues or larger energy infrastructures, a major challenge still resides in collecting the data and building the models required for this type of evaluation, with reasonable levels of reliability $[12,17]$.

\subsubsection{Primary Energy versus Exergy}

A second important sustainability aspect of the energy chain is its efficiency. More efficient energy use leads to reduced primary energy consumption and hence better sustainability scores. Although such effects should become manifest through LCA, it is advisable to conduct specific energy studies about primary energy use and exergetic efficiency for reasons of the particular insights they provide.

Expressing energy use in terms of primary energy consumption, on the one hand, provides a correct image of the real quantities of energy needed for a given application. For example, a passive house requiring $15 \mathrm{kWh} / \mathrm{m}^{2}$ per year for space heating and cooling based on typical current electricity mixes may require up to $40 \mathrm{kWh} / \mathrm{m}^{2}$ per year of primary energy through fossil fuel based electricity generation. Therefore, expression of consumption patterns in primary energy units deserves priority over current practices where this differentiation is not being made.

Exergy studies, on the other hand, provide a qualitative assessment of energy use. They allow for a complementary type of optimization, taking into account the intrinsic quality of an energy type in relation to its use [18]. Such an approach leads to fundamental insights, in particular with regard to the planning and design of the built environment [19]. In brief, exergy stands for the ability of a given quantity of energy to produce work. This quantity of work is not only dependent on the energy source, but as well on the surrounding environment. Therefore exergy (or work capacity) of a particular energy carrier must always be expressed with reference to the given environment.

A common (exergy related) problem of today's energy technologies is that they systematically demand high quality energy sources. One example is the combustion of high quality fossil fuels to provide for low quality energy applications such as space heating or cooling [18,20,21]. Or expressed in numbers, a typical home boiler burns natural gas at temperatures of over $1000{ }^{\circ} \mathrm{C}$ to provide space heating of around $20{ }^{\circ} \mathrm{C}$. The latter could also be realized by waste heat at $45^{\circ} \mathrm{C}$. Because of its novel character, the application of exergy considerations in the planning and design of the built environment is considered in more detail in the following paragraphs.

First of all, it should be remarked that a major share of the energy required in buildings is for heating and cooling, in a typical temperate climate around $70-80 \%$ for heating alone, e.g., [22,23]. 
Both applications aim at heat transfer processes that only require low exergy inputs, for example heating a space up to $22{ }^{\circ} \mathrm{C}$ or cooling it to $18{ }^{\circ} \mathrm{C}$ starting from temperatures that are in a close range. A similar remark can be made about domestic hot water, although the required temperature levels are higher in this case and so the exergetic quality of the energy source should increase accordingly. High quality sources like electricity are, by contrast, only strictly required for a specific range of building appliances, including household devices and lighting. Therefore, both combustion processes and electricity use should be avoided for space heating and cooling, and in a somewhat lesser degree, for domestic hot water production. Alternative, low-exergy heat or cold sources must be searched for. In practice, this could imply waste heat recovery, solar heat production and heat extraction from underground.

A group of experts working for IEA Annex 49 has researched this issue and recently brought together its findings and recommendations in a report on low exergy ('lowex') design strategies for buildings and communities [18]. Within the same project, software tools have been developed to assist designers in exergetic optimization. In the context of the discussion in this paper, it is important to note that the researchers of this project emphasize that exergy cannot be considered as a sustainability indicator ([18], p.114). Herein they differ from other scientists that will be discussed below. Some of the practical conclusions of the above study deserve particular attention because they help to define the constituents of a sustainable urban energy paradigm as discussed in the third section of this paper. Concerning renewable energy, both a large share of renewable sources and a high exergetic efficiency must be strived for simultaneously. In practice, trade-offs will have to be made. Solar based systems that take the heat immediately from the sun are favorable for two reasons: they help reducing primary (fossil fuel based) energy demand and optimize exergetic performance. The re-use of residual heat, especially from CHP, is another solid option. Heat pumps can be a good choice for low exergy systems, as far as their electricity use does not wipe out the advantages of using waste or ambient heat. This means in particular that the bridged temperature differences must remain rather small. As lowex energy systems make use of waste and ambient heat, considering the district, community or even regional scale becomes an important factor of optimization. This fits very well with the approach of 'energy potential mapping' or 'energy landscapes' as brought forward in several recent studies [24,25].

\subsubsection{A Unification Theory?}

Within the research field of exergy studies, another school exists where the concept of exergy is taken further than the strictly energetic optimization of energy flows. Hereby, the exergy accumulated into or extracted/dissipated from a natural or human system is taken into consideration in order to assess its overall resource efficiency. This can go as far as considering the exergy embedded in informational structures such as DNA. Following the same lines of thought, exergy could then be used as a sustainability indicator. In this context, Jørgensen uses the concept of 'eco-exergy' [26].

In order to assess these new research directions, a group of researchers has mapped the current state of affairs in an overview article [27]. They distinguish four paths of development: ecosystem analysis, industrial system analysis, (thermo-)economic analysis based on extended exergy accounting (EEA) and environmental impact assessment, for example through the Cumulative Exergy Extraction from the Natural Environment (CEENE) approach. The latter category aims at reconciling LCA, which is 
mainly focused on harmful emissions, with exergy by considering those negative environmental impacts in terms of their related exergy effects or through the exergetic cost of abating the emissions in case ([27], pp. 2228-2229). The authors argue that industrial system analysis and environmental impact assessment based on exergy have indeed a mature potential, while ecosystem analysis and thermo-economics remain controversial. Techniques like EEA or CEENE would moreover avoid the application of (subjective) weight factors, as occurs in LCA, through a unified comparison basis [27,28].

From a practical point of view however, case studies in this area illustrate the complexity of transferring extended exergy concepts to the daily practice of urban design, planning and construction $[26,28,29]$. Therefore we propose not to include them in the implementation framework proposed here, at least for the time being.

\subsubsection{The Altered 'Trias Energetica' or 'New Stepped Strategy' as an Analytical Work Tool}

In energy-related engineering, a common approach is to apply a principle known as the trias energetica [30]. This is a three-step method for increasing the sustainability of energy systems by respectively $1^{\circ}$ reducing the demand for energy, $2^{\circ}$ applying renewable energy sources wherever possible and $3^{\circ}$ filling in the remaining need as efficiently and cleanly as possible with fossil fuels. However, thinking of a renewable energy future and taking into account the exergy aspects mentioned above, a new version of the trias has meanwhile been proposed by van den Dobbelsteen and worked out in several research projects [20,31].

This altered trias or 'New Stepped Strategy' maintains the first step of the original sequence, inserts a new one and converts the fossil fuel part into a temporary, transitional step as follows ([20], p. 12):

01. Reduce consumption (using intelligent and bioclimatic design)

02. Reuse waste energy streams

03. Use renewable energy sources and ensure that waste is reused as food

04. (Supply the remaining demand cleanly and efficiently)

It is to be noted that the use of materials is now included in the strategy, but for the present discussion we will solely focus on the energy part. The second step targets the exergetic optimization discussed in Section 2.1.2, however without being exhaustive in its description. We will, for the sake of completeness, formulate a solidified trias or expanded 'stepped strategy' in Section 3 of this paper.

When comparing van den Dobbelsteen's proposal with the work of IEA Annex 49 [18], step 1 appears to remain largely valid from an exergetic point of view as well: reducing the energy demand is mostly effective for limiting the exergetic losses at the same time. By contrast, step 3 addresses the use of renewable energies which is, in the strict sense, not being considered through exergy analysis. As a conclusion, the new stepped strategy approach may be regarded as a solid strategy from both an energy and exergy point of view, as well as from an impact reduction/LCA point of view. It coherently addresses every side of the problem. Nevertheless, detailed energy/exergy and LCA studies will always allow fine-tuning the potential design options, and therefore remain desirable in many cases. 


\subsection{Environmental Assessment versus Integrated Sustainability Evaluation}

Urban development questions present complex decision contexts concerning ill-defined problems, in particular when integrated sustainable functioning is pursued [32,33]. Therefore, environmental assessments should in this context be complemented by an evaluation in the social, economic and policy/process realms, e.g., [5-8].

For the present discussion, we will group these dimensions together into a second step that aims at putting sharp the picture of integrated sustainable functioning. As a detailed analysis of sustainable urban development evaluation is beyond the scope of this article, we summarize a methodological approach based on multimodal system analysis to frame the present discussion [7,8,34-36]. The multimodal system theory states that reality manifests itself in human experience through independent modal aspects or law-spheres. In fact, these modal aspects can roughly be considered as knowledge fields. Herman Dooyeweerd, founder of the theory, identified 15 such spheres that logically succeed each other as follows: the numerical, the spatial, the kinetic, the physical, the biological, the sensitive-psychical, the analytical-logical, the historical-cultural, the linguistic-communicative, the social, the economic, the aesthetic, the jural, the ethical and the credal law-sphere [34]. Sphere sovereignty on the one hand and functional links between the law-spheres on the other hand, are two important characteristics of the modal aspects. For example, a law-sphere cannot exist without its 'substrate' of preceding spheres, but at the same time it is fundamentally different from the latter. Hereby the character of the modal aspects evolves from determinative (ruled by the laws of mathematics, physics or biology) to normative (regulated by human convention). Dooyeweerd's theory has been successfully applied in, among others, system sciences and sustainable urban development studies $[7,35,36]$. For the present analysis we thus propose an aspectual lecture of reality that has been interpreted in a way to formulate a series of principles for sustainable (urban) development (SD) [8]:

- The range of modal aspects concerning SD reaches until the ethic dimension (similar to the field of Human Rights), as we can derive from expressed sustainability descriptions such as the Brundtland definition [37]. Therefore SD requires more than a strict Planet, People, Prosperity approach, and should explicitly address the value-related trade-offs that characterize decision-making, in particular in the contexts of urban and spatial planning. These trade-offs are indeed deeply influenced by the social and ethic norms held by the actors involved in the decision process;

- Sustainability is thus a human normative concept. However, it remains founded in the biophysical world characterized by its own, deterministic laws. This implies that normative conventions describing sustainability should account of related biophysical effects. As an example, this is reflected in the structure of the Kyoto protocol where a normative convention on preventing climate change defines how much $\mathrm{CO} 2$ can be emitted. The amount of climate change (and therefore of carbon emissions) we judge to be acceptable is however based on a normative appreciation;

- In accordance with the former principles, no social or economic sustainability are possible without environmental sustainability for reasons of retrocipative foundation [34]. Weak sustainability (e.g., [38]) is therefore not feasible, or in other words, sustainable development is integrated, or it is not at all; 
- From an analytical point of view, a multidisciplinary framework is needed for the proper assessment of all the independent modal spheres concerned by SD;

- And thereby scientific disciplines deliver constitutive, although partial assessments through their specific idiom. Determinative (quantitative) idioms, as well as strictly social or economic idioms make up the building stones of an integrated assessment, but do not deliver an exclusive or autonomous ordeal by themselves. This observation holds in particular for monetizing techniques such as cost benefit analysis.

Based on the research mentioned higher, we opinion that a method considering these principles of extended sustainability assessment is beneficial for setting up a well-balanced design or planning process. In particular, the method allows situating questions of energy provision or intervention in the built environment in a wider landscape of mutual interferences. It facilitates structuring the question at hand through in-depth analysis, and thus helps to pave the way for informed assessment, design, and decision making.

\section{Constituents of the Sustainable Built Environment versus Constituents of the Renewable Energy Infrastructure}

In this section we aim at composing a methodologically coherent outline of the constituents of the transition towards sustainable urban energy futures, based on the concepts discussed in Section 2.

At this moment, and still for many years to come, renewable energy sources will not be able to replace the current volume of fossil energy consumption entirely. Therefore, when considering a transition towards $100 \%$ renewable sources, reducing energy demand will remain a prime objective, coming before any other consideration and thus reinforcing the first step of both the trias and the 'new stepped strategy' approach.

As discussed in Section 2.1.4, we propose to upscale the 'new stepped strategy' to fully account for the urban factors that come into play when considering the built environment as a whole. We thus arrive at the following principles (leaving out the fourth, transitional step):

1. Reduce energy demand by passive architectural and urban control measures: location choice, response to local climate and relief conditions, architectural and urban compactness, orientation and daylighting features, building insulation levels, use of thermal capacity and buffer spaces, insertion of natural elements for shading, wind braking and urban heat island reduction, etc. It is interesting to observe that many buildings and cities constructed prior to the industrial revolution heavily relied on this type of climate control because energy sources were scarce and costly (see e.g., [39]). Effects of urban morphology on traffic demand make up a second important contributing factor, and related savings in transport energy should as a principle also be considered as a passive benefit;

2. Optimize energy streams from an exergetic point of view. For the built environment, low temperature (and thus low exergy) heat sources are of particular importance. They however require proper building installations (e.g., floor or wall heating and heat storage facilities). A similar remark could be made about cooling. Moreover, in an urban context, cooling and heating demands exist simultaneously or can at least be time-buffered to do so. Therefore, 
two major constituents of exergy optimization emerge: direct sourcing of low exergy heat sources (solar heat, ambient heat, recovery of waste heat, etc.), and heat exchange and storage between different building programs.

3. Provide renewable energy to fill in the remaining demand. This energy may be provided at the following three scale levels: single building (intra-urban micro-scale), building group/district (intra-urban meso-scale), or city/region (extra-urban macro-scale). The question which energy provision is most appropriate at which scale level shall basically be answered through an assessment as discussed in Section 2. It thus concerns an efficiency matter, but needs embedding in a wider framework of SD goals.

Some further observations can be made regarding the constitutive elements of this expanded stepped strategy.

\subsection{Reducing Urban Energy Demand through Passive Measures}

When considering the impact of urban energy use in buildings, several contributing factors may be distinguished as represented in Figure 1, based on [40,41]. The impact is determined by the quantities of the different energy uses multiplied by the environmental impact of every used energy type. When looking at the typical ranges of difference between good and bad performance, the factors displayed in Figure 1 appear. It is to be noted that simply multiplying the separate limit values for obtaining the overall variation range is not correct, since the contributing factors influence each other. Rebounds, for example low energy bills, may cause inhabitants of a passive house to waste more energy through lighting and household appliances.

Figure 1. Contributing factors to the amount of energy needed, and corresponding environmental impact, of intra-building energy use. Urban morphology and building design indicate the potential of passive design measures. Scheme based on [40,41]. The location aspect (relief and climate) is not considered here.

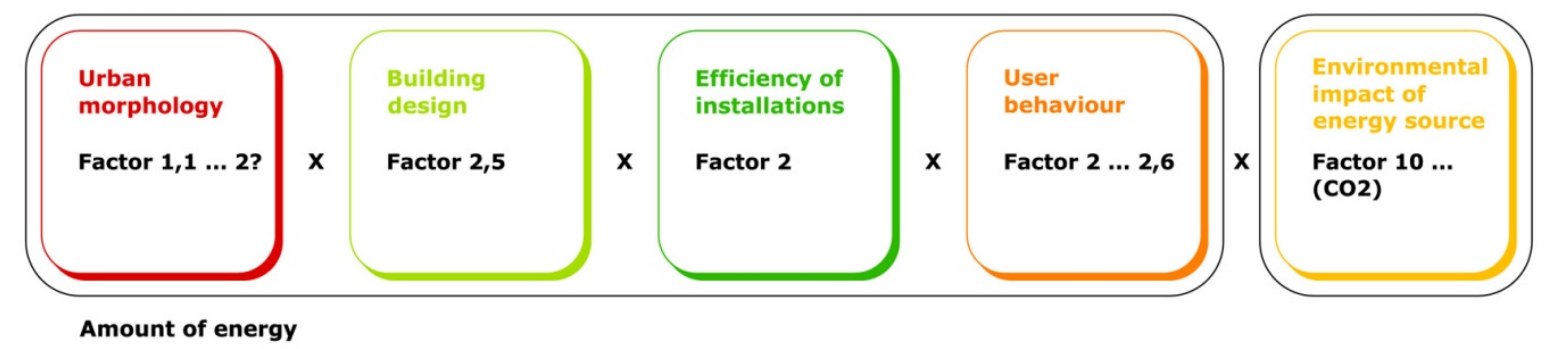

Among the above factors, urban morphology and building design should be considered as the pre-eminent passive design variables that can make a difference with regard to sustainable performance.

Estimations on the role of urban morphology in terms of building textures vary considerably. Ratti, Baker and Steemers arrived at variations in the order of magnitude of $10 \%$, considering heating and cooling, lighting and ventilation [41]; whereas Salat identified 80\% differences for heating energy and concludes, more generally, that urban morphology can make up for a factor 2 in energy use variations $[40,42]$. 
In addition, this analysis does not yet include higher order design parameters concerning location choice and the related effects of site, relief, vegetation and local climate. This is in fact a parameter that has been historically important, but later ignored, especially in the era of technological innovation and urban expansion that has come with the industrial revolution. If any, the focus in the past was on energy conservation through careful site planning, climate-responsive building techniques and proper use of vegetation and water structures [43-45] (Figure 2). A renewed interest in these aspects can now be found in studies inquiring the influence of vegetation on the urban climate, and in particular the urban heat island [46-48]. In a similar way, vegetation and water structures are gaining wider interest for their potential contribution to climate adaptation strategies within cities.

Figure 2. Climate-sensitive and passive design in traditional architectures: (a) urban palace in Damascus, with inner patio, an iwan as a half-outdoor living space and a central pond for evaporative cooling; (b) house in Romania with veranda for shading (open part) and as a buffer space (closed part); (c) double façade houses in La Coruña, Spain, where the galerias create an intermediate zone protecting and regulating the climate in the house behind; (d) rural house in the wind-exposed polders of the Belgian coastal region, with an arrangement of protective greenery. Image source: authors.

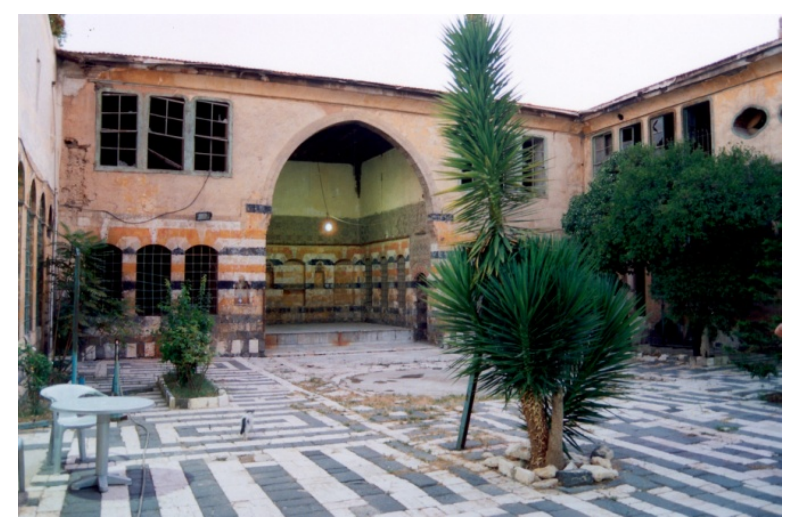

(a)

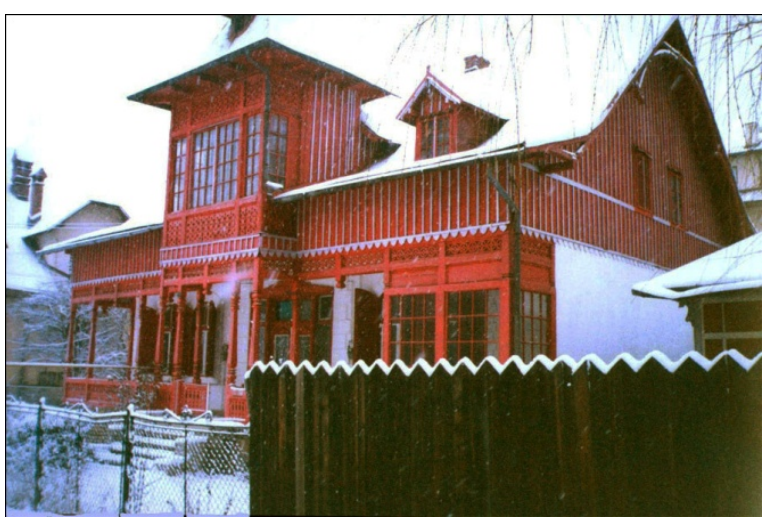

(b)

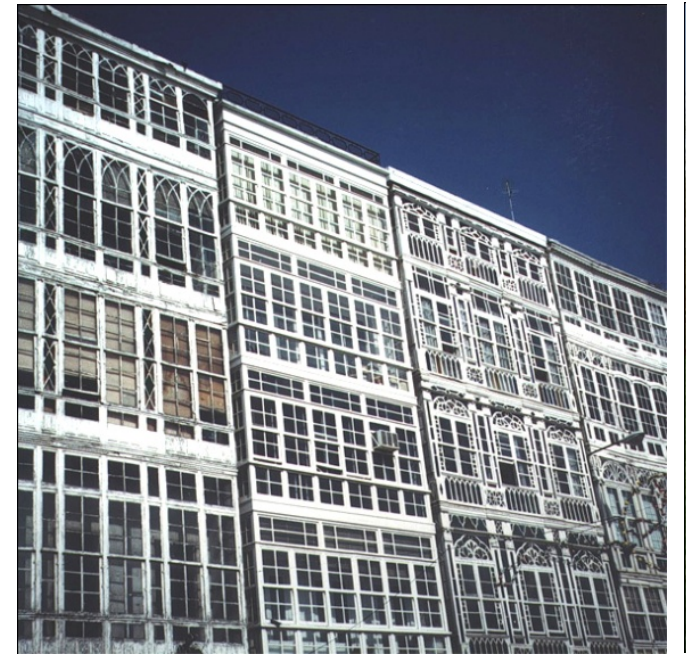

(c)

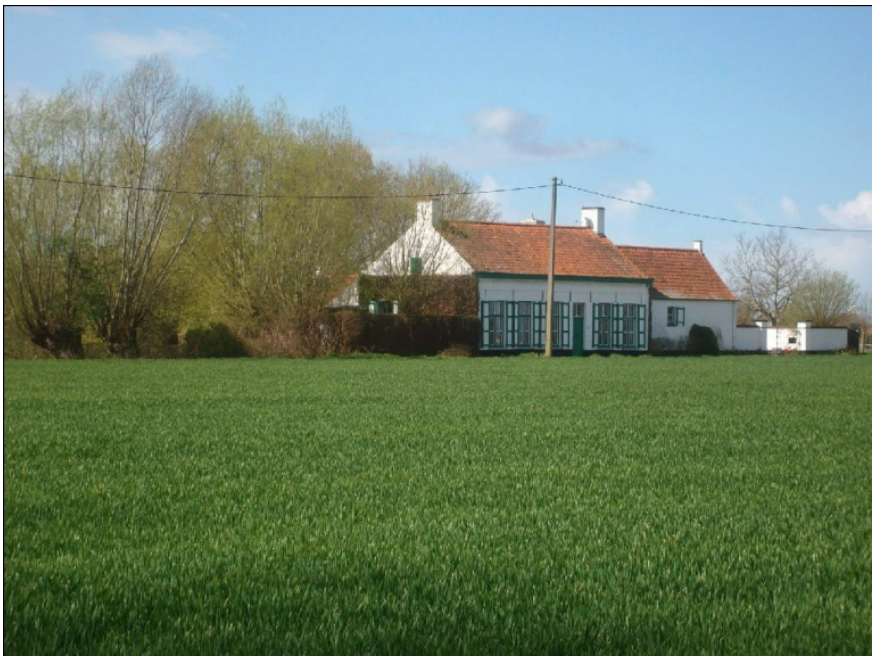

(d) 
Increasing urban compactness must hereby not become an absolute principle. There are quantitative as well as qualitative reasons for restricting the compaction to certain limits. First, energy consumption in compact and deep structures will increase by the rising need for artificial lighting and mechanical ventilation ([41], pp. 772-773). Second, qualitative requirements like the access to daylight in living and working spaces or the sufficient availability of open, green areas within the city put equally a limit on the compactness of the urban texture. Consequently, defining optimum morphology and compactness is an extremely difficult and location-specific task, regardless of the energy or sustainability parameters under consideration.

While urban morphology is an aspect that has until recently remained undervalued, the influence of the individual building design is better known. Orientation, glazing ratios, building envelope characteristics and thermal capacity define the major passive impacts on energy use [23,49].

When considering the influence of urban morphology on energy needs for transport, general propositions such as the hyperbolic correlation between urban density and personal transport energy derived by Newman and Kenworthy [50] may be challenged in particular local situations, not least because transport user choices and behavior are fairly unpredictable. Urban compactness appears to facilitate, but not necessarily to guarantee, reduced transport energy demand. The estimation of related transport impacts, for example at the neighborhood scale, thus becomes a daunting task. Surveys have proven to be a way of monitoring the real outcomes of the many mutually interfering aspects of urban transport. Examples hereof can be found in some flagship sustainable neighborhood projects, e.g., Hammarby Sjöstad (Stockholm) ([51], pp. 6-7) and BedZED (London) ([52], pp. 26-28). For Hammarby, a compact brownfield redevelopment with good public transport connections to Stockholm's city center, CO2-emissions related to private car use were found to be $50 \%$ lower than for reference mobility patterns. In a similar way, private car mileage in BedZED was estimated to drop some $65 \%$ under the British average.

From these observations, we may conclude that the general principles of passive urban design appear as relatively robust, including transport related issues, but that detailed studies are essential when intervening in particular contexts. These detailed studies will depend upon proper methodologies and data sets at the planning stage of an urban project. Apart from environmental and cost efficiencies, a number of qualitative parameters have to be taken into account, as discussed in Section 2.2.

It should be noted that compact urban and building structures also facilitate savings in the required amounts of construction materials (e.g., [53]). Research on building insulation has indicated that the energetic pay-back times of insulating materials are relatively short [16]. In conclusion, these types of passive energy-saving measures can concur well with the overall goal of reducing total environmental impact, and therefore the first action of the stepped strategy remains principally uncontested.

\subsection{Exergetic Optimization of Building Related Energy Streams}

As argued above, it is essential to differentiate between energy qualities when considering building related energy streams. Taking into account the observations made in Section 2, a fairly new branch of research called energy potential mapping investigates the opportunities for optimized exergetic use of available energy sources at the urban and regional scale levels [20,24,31,54]. Hereby the spatial aspect of energy potentials becomes critical for two reasons. 
First, electricity and heat (or cold) are characterized by different transportation and storage possibilities. In basic terms and considering the present state of affairs, this may be resumed as electricity being easy to transport and difficult to store, while the opposite applies to heat and cold [19]. As a result, local heat and cold applications are feasible within the built environment, while the generation of electricity can be delocalized at larger distances from the consumers where appropriate. Some nuances must be made, however. In the future, electricity storage may become more feasible, for example by using car batteries as a storage medium within smart grids (e.g., [55]). Exploiting beneficial interferences between electricity and heat/cold applications is another aspect that gains importance (e.g., [56]). The upscaled storage of heat and cold can be achieved with buffer tanks of increasing size, e.g., concrete or polymer tanks containing up to several thousands of $\mathrm{m}^{3}$ of water (e.g., [57], Figure 3), but also by using the underground as a free reservoir through the different types of geothermal storage (aquifer-, soil-, or cavity-based).

Figure 3. Solar boiler field with storage tank on the island of Samsø, Denmark. Directly sourcing solar energy is favorable from an exergetic point of view. If the heat can be efficiently stored for matching supply and demand, the disadvantage of the variability of the renewable source can be partially overcome. Image source: authors.

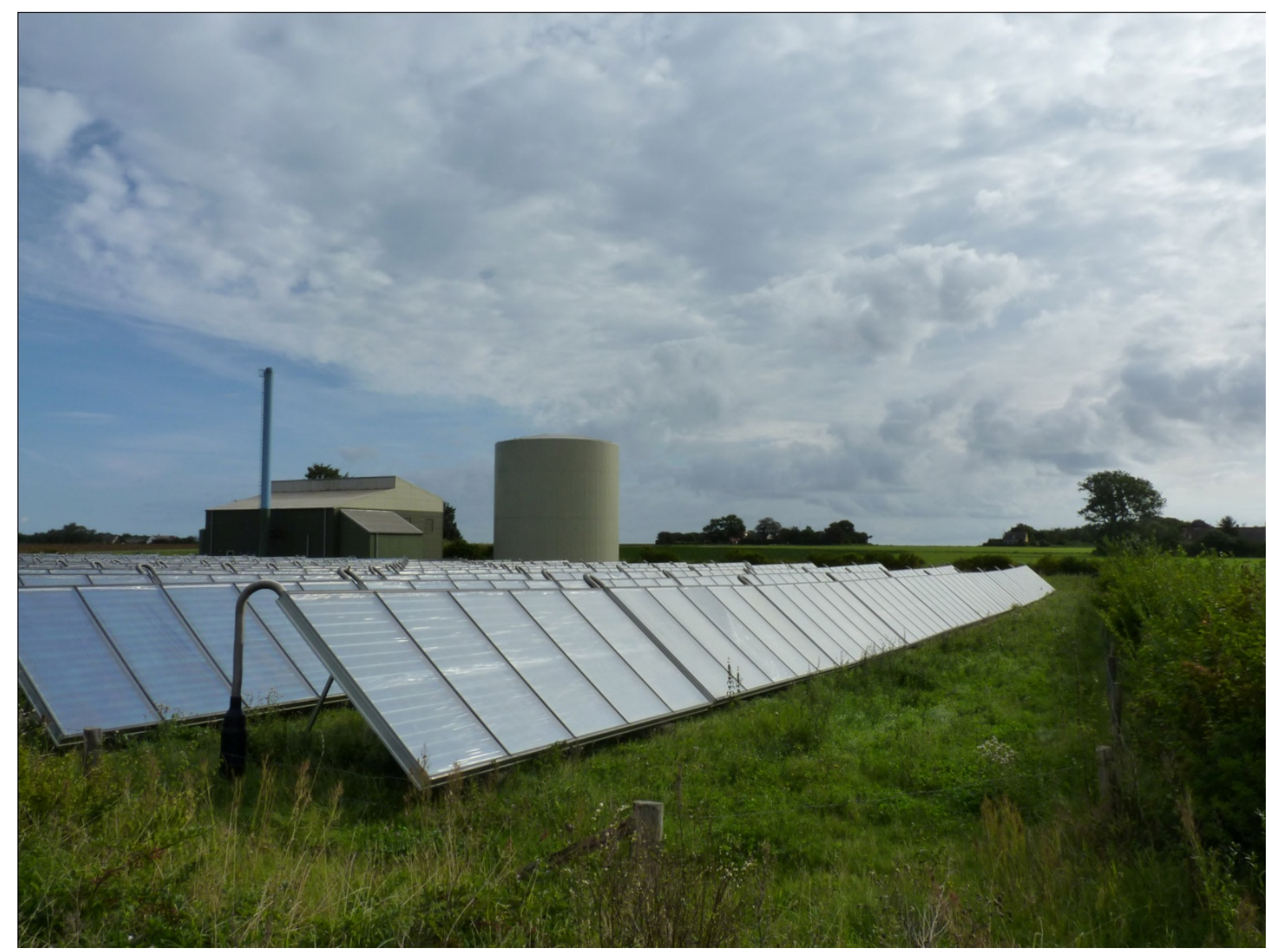

This leads to a second aspect illustrating the importance of spatial planning in the energy equation: all of the building related energy infrastructures must find their place either on or below the ground. Spatial arrangements and distances between applications thus become an important consideration. 
Moreover, as it was the case for the reduction of the energy demand, an optimization in the environmental sense alone will not be sufficient to arrive at sustainable solutions. Spatial planning involves many other social, economic, juridical as well as historic, cultural and aesthetic aspects having a decisive influence on the feasibility of any proposed intervention. This complex exercise leads to urban or regional energy plans such as worked out, for example, in the Dutch SREX and Lowex research projects (e.g., [31], Figure 4).

Figure 4. Extract of a spatially explicit energy vision for the region of Southeast Drenthe, The Netherlands. The map shows how renewable and residual energy sources can be integrated in a regional energy landscape with its urban, industrial and rural functions (composed image based on [31]).

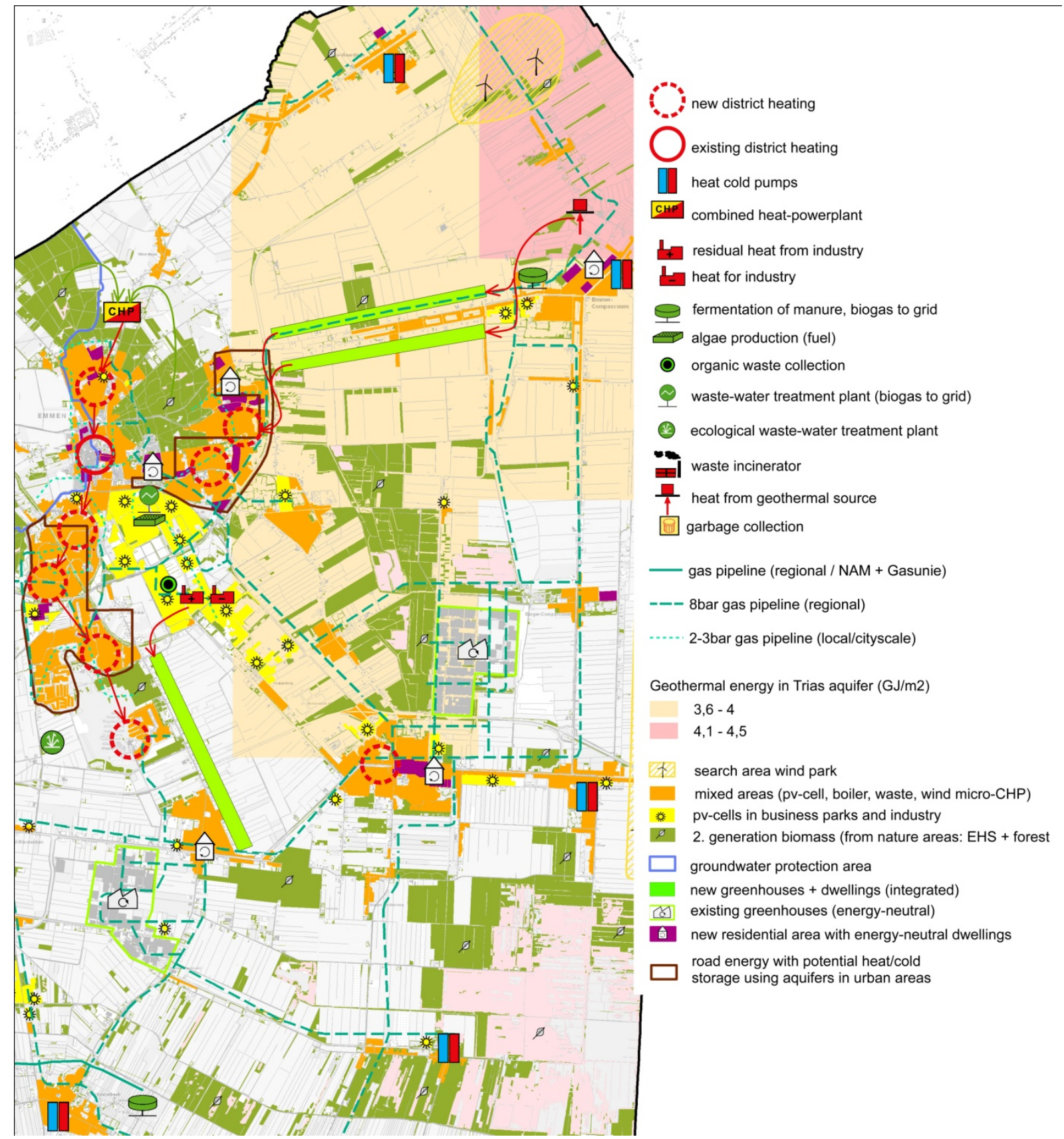


Two types of application, waste heat recovery and exchange of heat and cold, deserve particular attention. Waste heat recovery is most feasible from high temperature industrial and electricity generation processes, and enables the cascading of heat through low temperature applications in the built environment. Heat exchange between building programs, on the other hand, is possible between net suppliers and demanders. Another optional but related strategy is to store excess heat or cold until it can be used. Here, the more known shallow geothermal applications come in view and perhaps gain more momentum in the near future. One example is to manage the demand and supply of both heat and cold on the neighborhood or district level.

District heating and cooling networks are defined by similar operational conditions. The heat or cold demand should be sufficiently high and spatially concentrated to allow for satisfactory efficiency, both in environmental and in economic terms. Regarding the important question if district heating remains interesting in combination with low energy building districts, a Danish case study points out that this can be the case if transmission losses in the network are reduced to the maximum, combined with the use of heat storage tanks in the serviced buildings [18]. The opposite situation appears in historic town centers, where it is difficult to upgrade all of the building patrimony to low energy or passive standards. Here it may be efficient to invest in district heating and cooling, while at the same time topping the efforts in building renovation to levels that are environmentally responsible, yet culturally acceptable and economically feasible.

Therefore, first of all, an environmental evaluation should allow formulating adequate and sufficiently precise trade-offs between the available applications. Which scenario delivers the best energy/exergy/LCA-scores? Economic, social and other qualitative assessments should then build further on the outcome of this environmental evaluation.

In practice, a deeper level of restructuring and life cycles must be addressed as well. Since the built environment has a high permanence, questions regarding the very long term (more than 100 years) should be considered. This is linked to the fact that the rotation in the built environment is typically around one or a few per cent per year (e.g., [2], p.59). How shall the building stock evolve to realize increasing sustainable performance? This means that, for example, the following type of problem needs an address: is renovation the best option; is it demolition and rebuilding; or is it demolition and building at another location? A similar reflection should be made concerning energy infrastructures whose life cycle may span across even longer periods of time [25]. Each of these options may deliver other preferable energy systems.

The fact that both the energy and exergy efficiency of the current transport sector are poor (e.g., [28]), further emphasizes the need to address mobility as well, and this at all levels (demand, modal switch, technology).

\subsection{Renewable Energy Provision}

Renewable energy provision may take place at three scale levels, which can be conceptualized as follows:

- Macro-scale: large hydropower, wind farms, concentrated solar power plants (CSP), large-scale solar parks, large biomass plants, deep geothermal heat and/or electricity generation. This scale is somewhat similar to current electricity production patterns; 
- Meso-scale: district systems including CHP plants and related networks, mid-scale solar applications such as asphalt collectors and small to medium solar fields (PV or heat), geothermal applications at the district scale (open heat/cold systems);

- Micro-scale: renewable production at the scale of the individual building: mainly PV, solar boilers, micro CHP and closed heat/cold systems.

In theory, a purely technical trade-off could define which applications are most favorable in a given design context. As mentioned for the other constituents, there are however many more factors to be considered. This results in a complex decision making process, especially for urban planning concerned with long term development. In how far may one, for example, expect that a smart grid or super grid will be available within a few decades?

At the supranational scale, research has indicated that Europe and its neighbors can have electricity based for $100 \%$ on renewable sources under the condition that a super grid is created throughout Europe and its neighboring territories (in particular North Africa and parts of Russia) [58]. Therefore, technically spoken, this option delivers an important potential for filling in urban demands that cannot be met locally or within the proper regional context.

In a case study from Austria, Wächter et al. stress that "Critical issues are region-specific production of energy and its use, settlement and regional structures and values and role models, which all have a determining influence on energy demand." ([59], p. 193). Energy-intensive land use patterns (urban sprawl,...) are a hard nut to crack when it comes to rendering these structures more sustainable: both settlement structures with their mobility patterns, and energy infrastructures, should be profoundly transformed over the coming decades.

In another case study for a renewable energy system in the region of the Peat Colonies in the Netherlands, a strategy was proposed where areas with high renewable energy potential will have to invest less in energy savings whereas areas with small renewable energy potentials will have to focus on savings even more [60]. This proposal-to determine ambition targets for both renewable energy provision and energy savings based on the local energy potentials - once again stresses the need to map energy potentials prior to any decision with regards to alternative energy systems.

Diversity is another relevant criterion to be added for robust energy systems at all scales [61]. It implies that sources and technologies replace each other when failures appear or shortages occur. In addition, a diversified energy system can deal with intermittencies between energy supply and demand.

From this discussion it becomes clear that the third step-renewable energy provision-goes beyond individual interventions at the building or urban scale. Urban energy problems should, at all times, be considered within their regional energy landscapes. Amongst other benefits, this accommodates for the low density (or high demand for land) of most renewable energy sources. Cities should, however, also be enabled to connect to future super grids. This is especially important as macro-scale electricity generation presents itself as an environmentally efficient means of energy provision that can compensate for the lack of resources within cities and towns. 


\section{Discussion and Conclusions}

In the previous sections we have adopted a bird's eye perspective on the challenges for renewable energy based urban planning, all from a designer's standpoint. In Section 2 we proposed an analytical framework for addressing these challenges. We distinguished two levels of analysis: (a) environmental, and (b) integrated with a view on sustainable development. Taking into account recent insights on the importance of low exergy design, we have come to the conclusion that an altered trias energetica is a robust and useful concept for addressing environmental aspects in urban design. Although exergy remains a controversial concept, especially when it is taken out of its strict energetic context, we are convinced that it deserves particular attention in future planning practice and research. The somewhat limited capacity to serve as a more holistic sustainability indicator implies that other sustainability assessments remain important.

In Section 3 we zoomed in on the practical building stones of urban networks sustained by renewable energy. To our opinion, inquiring the role of urban morphology in relation to energy needs and exploring energy-conscious spatial planning are two main directions for further research and application in real world experiments.

A wide range of research horizons has to be considered in order to arrive at a synthetic view of the problems considered in this article. Hence, inter- and transdisciplinary research is essential for tackling problems of sustainable urban development. As argued in Section 2.2, environmentally sustainable schemes can thereby not be realized without linking to the social, cultural, economic, juridical, aesthetical, political and ethical spheres as well. For long, these spheres have been the 'battleground' for urban planners and designers and, we expect, will remain so also with regard to the energy transition. A systems perspective questioning the all too common business as usual scenarios is inevitable. In their discussion of a sustainable energy transition in Austria, Wächter et al. come to a similar conclusion when stating that the "... societal transformations towards a sustainable energy system are explicitly normative and value-laden and driven by the need to break with a business-as-usual path" ([59], p. 199). At the same time, many opportunities lie ahead.

Transiting to a renewable energy supply can result in secondary benefits such as healthy and convivial city centers, green jobs and increased welfare in more general terms. For the built environment, an important part of the transition effort can thereby be realized at a net profit from the economical point of view [62-64]. The renovation/transformation of the existing building stock is indeed the most promising field for climate-related intervention, under the condition that a life cycle costing approach is maintained and that certain environmental burdens, in particular CO2-emissions, are properly taxed. From a designer's perspective, we must stress the need to include energy-conscious strategies at every stage of the planning process.

Finally, we consider this article as an invitation to open the debate on matters of 'hands on' energy-conscious urban planning. Today, we are confronted with a situation of urgently needed societal change while many of the tools needed to realize the energy transition are already at hand. What remains to be done is to creatively connect the missing links, both in research and application. The integration of new knowledge, changing societal values and innovative technologies in the sustainable transformation of the built environment remains a great challenge for urban planners and designers in many contexts. 


\section{Conflict of Interest}

The authors declare no conflict of interest.

\section{References}

1. van Kann, F.; Leduc, W. Synergy between Regional Planning and Energy as a Contribution to a Carbon Neutral Society-Energy Cascading as a New Principle for Mixed Land-use. In Proceedings of the Scupad Conference: Planning for the Carbon Neutral World: Challenges for Cities and Regions, Salzburg, Austria, 15-18 May 2008.

2. Vandevyvere, H. Strategieën voor een Verhoogde Implementatie van Duurzaam Bouwen in Vlaanderen. Toepassing op het Schaalniveau van het Stadsfragment (Strategies Towards Increased Sustainable Building in Flanders. Application on the Scale of the Urban Fragment). Ph.D. Dissertation, K.U. Leuven, Leuven, Belgium, 2010.

3. Stöglehner, G.; Narodoslawsky, M. Energy-conscious Planning Practice in Austria: Strategic Planning for Energy-optimized Urban Structures. In Sustainable Energy Landscapes: Designing, Planning and Development; Stremke, S., van den Dobbelsteen, A., Eds.; Taylor \& Francis: Boca Raton, FL, USA, 2012.

4. Allacker, K. Sustainable Building: The Development of an Evaluation Method; K.U.Leuven: Leuven, Belgium, 2010.

5. French, S.; Geldermann, J. The varied contexts of environmental decision problems and their implications for decision support. Environ. Sci. Policy 2005, 8, 378-391.

6. Deakin, M.; Mitchell, G.; Nijkamp, P.; Vreeker, R. Introduction. In Sustainable Urban Development Volume 2: The Environmental Assessment Methods; Deakin, M., Mitchell, G., Nijkamp, P., Vreeker, R., Eds.; Routledge: London, UK, 2007.

7. Lombardi, P.; Brandon, P. The Multimodal System Approach to Sustainability Planning Evaluation. In Sustainable Urban Development Volume 2: The Environmental Assessment Methods; Deakin, M., Mitchell, G., Nijkamp, P., Vreeker, R., Eds.; Routledge: London, UK, 2007.

8. Vandevyvere, H. How to cut across the catch-all? A philosophical-cultural framework for assessing sustainability. Int. J. Innov. Sustain. Dev. 2011, 5, 403-424.

9. U.S. Green Building Council. LEED 2009 for Neighborhood Development Rating System (Updated November 2011); U.S. Green Building Council: Washington, DC, USA, 2011.

10. BRE BREEAM Communities. SD5065B. Technical Guidance Manual; BRE Global Ltd: Watford, UK, 2009.

11. ISO. ISO 14040:2006 Environmental Management-Life Cycle Assessment-Principles and Framework; ISO: Geneva, Switzerland, 2006.

12. Sørensen, B. Life-Cycle Analysis of Energy Systems: From Methodology to Applications; Royal Society of Chemistry Publishing: Cambridge, UK, 2011.

13. Goedkoop, M.; Spriensma, R. The Eco-indicator 99 Methodology Report: A Damage Oriented LCIA Method; Ministerie van Volkshuisvesting, Ruimtelijke Ordening en Milieubeheer: Den Haag, The Netherlands, 1999. 
14. Dones, R.; Heck, T. LCA-based Evaluation of Ecological Impacts and External Costs of Current and New Electricity and Heating Systems. In Proceedings of the Material Research Society Fall Meeting 2005, Symposium G: Life Cycle Analysis Tool for 'Green' Materials and Process Selection, Boston, MA, USA, 28-30 November 2005.

15. Kampman, B.; Bergsma, G.; Schepers, B.; Croezen, H.; Fritsche, U.R.; Henneberg, K.; Huenecke, K.; Molenaar, J.W.; Kessler, J.J.; Slingerland, S.; van der Linde, C. BUBE: Better Use of Biomass for Energy (Background Report to the Position Paper of IEA RETD and IEA Bioenergy); CE Delft/Öko-Institut: Delft, The Netherlands and Darmstadt, Germany, 2010.

16. Verbeeck, G. Optimisation of Extremely Low Energy Residential Buildings. Ph.D. Dissertation, K.U. Leuven, Leuven, Belgium, 2007.

17. Kohler, N. Life Cycle Analysis of Buildings, Groups of Buildings and Urban Fragments. In Sustainable Urban Development Volume 2: The Environmental Assessment Methods; Deakin, M., Mitchell, G., Nijkamp, P., Vreeker, R., Eds.; Routledge: London, UK, 2007.

18. Torio, H.; Schmidt, D. ECBCS Annex 49-Low Exergy Systems for High Performance Buildings and Communities (Annex 49 Final Report); Fraunhofer IBP/IEA: München, Germany, 2011.

19. Stremke, S.; van den Dobbelsteen, A.; Koh, J. Exergy landscapes: Exploration of second-law thinking towards sustainable landscape design. Int. J. Exergy 2011, 8, 148-174.

20. Tillie, N.; van den Dobbelsteen, A.; Doepel, D.; de Jager, W.; Joubert, M.; Mayenburg, D. REAP Rotterdam Energy Approach and Planning: Towards CO2-Neutral Urban Development; Pieter Kers: Rotterdam, The Netherlands, 2009.

21. Schmidt, D. Low exergy systems for high-performance buildings and communities. Energy Build. 2009, 41, 331-336.

22. Van Steertegem, M.E. MIRA-T Milieurapport Vlaanderen, Indicatorrapport '07; Vlaamse Milieumaatschappij: Aalst, Belgium, 2007.

23. Hens, H. Duurzaam Bouwen; Francqui Leerstoel, Vrije Universiteit Brussel: Brussel, Belgium, 2006.

24. van den Dobbelsteen, A.; Broersma, S.; Stremke, S. Energy potential mapping for energy-producing neighborhoods. Int. J. Sustain. Build. Technol. Urban Dev. 2011, 2, 170-176.

25. Stremke, S.; Kann, F.V.; Koh, J. Integrated visions (Part I): Methodological framework. Eur. Plan. Stud. 2012, 20, 305-320.

26. Jørgensen, S.E. Eco-Exergy as Sustainability; WIT Press: Southhampton, UK, 2006.

27. Dewulf, J.; Van Langenhove, H.; Muys, B.; Bruers, S.; Bakshi, B.R.; Grubb, G.F.; Paulus, D.M.; Sciubba, E. Exergy: Its potential and limitations in environmental science and technology. Environ. Sci. Technol. 2008, 42, 2221-2232.

28. Sciubba, E.; Bastianoni, S.; Tiezzib, E. Exergy and extended exergy accounting of very large complex systems with an application to the province of Siena, Italy. J. Environ. Manag. 2008, 86, 372-382.

29. Jørgensen, S.E. Employing Exergy and Carbon Models to Determine the Sustainability of Alternative Energy Landscapes. In Sustainable Energy Landscapes: Designing, Planning and Development; Stremke, S., van den Dobbelsteen, A., Eds.; Taylor \& Francis: Boca Raton, FL, USA, 2012. 
30. Lysen, E.H., The Trias Energetica: Solar Strategies for Developing Countries. In Proceedings of the Eurosun Conference, Freiburg, Germany, 16-19 September 1996.

31. Broersma, S.; van den Dobbelsteen, A. Synergie Tussen Regionale Planning en Exergie: SREX; Publikatieburo Bouwkunde: Delft, The Netherlands, 2011.

32. Bauler, T. Indicators for Sustainable Development: A Discussion of Their Usability. Ph.D. Dissertation, Université Libre de Bruxelles, Brussels, Belgium, 2007.

33. Mondini, G.; Valle, M. Environmental Assessments Within the EU. In Sustainable Urban Development Volume 2: The Environmental Assessment Methods; Deakin, M., Mitchell, G., Nijkamp, P., Vreeker, R., Eds.; Routledge: London, UK, 2007.

34. Dooyeweerd, H. A New Critique of Theoretical Thought, Vol. 2: The General Theory of the Modal Spheres; The Presbyterian and Reformed Publisher Company: Phillipsburg, NJ, USA, 1955.

35. De Raadt, J.D.R. A sketch for humane operational research in a technological society. Syst. Pract. 1997, 10, 421-441.

36. Basden, A. The critical theory of Herman Dooyeweerd? J. Inf. Technol. 2002, 17, 257-269.

37. WCED. Our Common Future (Brundtland Report); United Nations-World Commission on Environment and Development: Geneva, Switzerland, 1987.

38. Cabeza-Gutés, M. The concept of weak sustainability. Ecol. Econ. 1996, 17, 147-156.

39. Knowles, R.L. Energy and Form: An Ecological Approach to Urban Growth; MIT Press: Cambridge, MA, USA, 1974.

40. Salat, S. Energy loads, CO2 emissions and building stocks: Morphologies, typologies, energy systems and behaviour. Build. Res. Inf. 2009, 37, 598-609.

41. Ratti, C.; Baker, N.; Steemers, K. Energy consumption and urban texture. Energy Build. 2005, 37, 762-776.

42. Salat, S.; Nowacki, C. De l'importance de la morphologie dans l'efficience énergétique des villes. Energ. Territ. Liaison Energ. Francoph. 2010, 86, 141-146.

43. Brown, R.D.; Gillespie, T.J. Microclimatic Landscape Design: Creating Thermal Comfort and Energy Efficiency; John Wiley \& Sons: New York, NY, USA, 1995.

44. Robinette, G.O.; McClenon, C. Landscape Planning for Energy Conservation; Van Nostrand Reinhold: New York, NY, USA, 1983.

45. Thompson, J.W.; Sorvig, K. Sustainable Landscape Construction: A Guide to Green Building Outdoors; Island Press: Washington, DC, USA, 2000.

46. Shashua-Bar, L.; Hoffman, M.E.; Tzamir, Y. Integrated thermal effects of generic built forms and vegetation on the UCL microclimate. Build. Environ. 2006, 41, 343-354.

47. Gill, S.E.; Handley, J.F.; Ennos, A.R.; Pauleit, S. Adapting cities for climate change: The role of the green infrastructure. Built Environ. 2007, 33, 115-133.

48. Alexandri, E.; Jones, P. Temperature decreases in an urban canyon due to green walls and green roofs in diverse climates. Build. Environ. 2008, 43, 480-493.

49. Santamouris, M. Environmental Design of Urban Buildings: An Integrated Approach; Earthscan Publications: London, UK, 2006.

50. Newman, P.; Kenworthy, J.R. Cities and Automobile Dependence: An International Sourcebook; Gower: Aldershot, UK, 1989. 
51. Brick, K. Report Summary - Follow Up of Environmental Impact in Hammarby Sjöstad by Sickla Udde, Sickla Kaj, Lugnet and Proppen; Grontmij AB: Stockholm, Sweden, 2008.

52. Hodge, J.; Haltrecht, J. BedZED Seven Years on: The Impact of the UK's Best Known Ecovillage and Its Residents; BioRegional: Hackbridge, UK, 2009.

53. van den Dobbelsteen, A.; de Wilde, S. Space use optimisation and sustainability-Environmental assessment of space use concepts. J. Environ. Manag. 2004, 73, 81-89.

54. Ramachandra, T.V.; Shruthi, B.V. Spatial mapping of renewable energy potential. Renew. Sustain. Energy Rev. 2007, 11, 1460-1480.

55. Clement-Nyns, K.; Haesen, E.; Driesen, J. The impact of vehicle-to-grid on the distribution grid. Electr. Power Syst. Res. 2011, 81, 185-192.

56. Saelens, D. Optimale Inzet van Thermische Opslag en Actieve Energieconcepten in Gebouwen om Maximaal in te Spelen op de Elektriciteitsmarkt en Behoeften van het net. 2011. Available online: http://www.kuleuven.be/onderzoek/onderzoeksdatabank/project/3E11/3E1100 62.htm (accessed on 18 June 2012).

57. Bühl, J. Solarenergienutzung und Effizienzsteigerung in und an Gebäuden. In Klimawandel und ökologischer Umbau der Industriegesellschaft; Europäischen Informations-Zentrum in der Thüringer Staatskanzlei: Erfurt, Germany, 2010.

58. Czisch, G. Scenarios for a Future Electricity Supply - Cost-Optimized Approaches to Supplying Europe and its Neighbours with Electricity from Renewable Energies. Ph.D. Dissertation, Universität Kassel, Kassel, Germany, 2006.

59. Wächter, P.; Ornetzeder, M.; Rohracher, H.; Schreuer, A.; Knoflacher, M. Towards a sustainable spatial organization of the energy system: Backcasting experiences from Austria. Sustainability 2012, 4, 193-209.

60. Roggema, R. INCREASE II Conference Proceedings; Province of Groningen: Groningen, The Netherlands, 2009.

61. Stremke, S.; Koh, J. Integration of ecological and thermodynamic concepts in the design of sustainable energy landscapes. Landsc. J. 2011, 30, 194-213.

62. Barker, T.; Bashmakov, I.; Bernstein, L.; Bogner, J.E.; Bosch, P.R.; Dave, R.; Davidson, O.R.; Fisher, B.S.; Gupta, S.; Halsnæs, K. et al. Technical Summary. In Climate Change 2007: Mitigation. Contribution of Working Group III to the Fourth Assessment Report of the Intergovernmental Panel on Climate Change; Metz, B., Davidson, O.R., Bosch, P.R., Dave, R., Meyer, L.A., Eds.; Cambridge University Press: Cambridge, UK and New York, NY, USA, 2007.

63. Jaeger, C.; Paroussos, L.; Mangalagiu, D.; Kupers, R.; Mandel, A.; Tàbara, J. A New Growth Path for Europe: Generating Prosperity and Jobs in the Low-Carbon Economy; Synthesis Report; European Climate Forum e.V.: Potsdam, Germany, 2011.

64. McKinsey-and-Company Pathways to World-Class Energy Efficiency in Belgium; McKinsey \& Company: Brussels, Belgium, 2009.

(C) 2012 by the authors; licensee MDPI, Basel, Switzerland. This article is an open access article distributed under the terms and conditions of the Creative Commons Attribution license (http://creativecommons.org/licenses/by/3.0/). 